\title{
Partial Replacement of Cement Concreete with Biological Green Waste
}

\author{
Tolmatti Vamshi Krishna ${ }^{1}$, M.Ashwin Kumar ${ }^{2}$ and Kunchala Anjaneyulu ${ }^{3}$ \\ ${ }^{1} P G$ Student, Vidya Jyothi Institute of Technology, Hyderabad, Telangana, India. \\ Email:tvk3418@gmail.com \\ ${ }^{2}$ Assistant Professor, Vidya Jyothi Institute of Technology, Hyderabad, Telangana, India. \\ Email: ashwinkumarmogulamadka@gmail.com \\ ${ }^{3}$ Assistant Professor, Sri Sai Jyothi Engineering College, Hyderabad, Telangana, India.
}

\begin{abstract}
:
Bagasse ash (BA), the residue obtained after the burning of sugarcane bagasse as a fuel, has pozzolanic properties with potential use as a supplementary binding material (SCM). Use of Bagasse ash (BA) as a mineral admixture needs to be established, especially in India, where sugarcane cultivation is widespread, to reduce land required for its disposal and cement consumption in construction industry. Hence, to encourage commercial use ofBA with minimum processing, an evaluation of the physical, chemical and morphological characteristics of a locally available BA and its effect, as SCM on properties of structural concrete was taken up.

This research work describes the feasibility of using the Fly Ash (FA) Rice Husk Ash (RHA) and Sugarcane Bagasse Ash(SCBA) waste in concrete production as a partial replacement of cement. This present work deals with the effect on strength and mechanical properties of concrete using Triple blending of cement concrete using FA, RHA and SCBA instead of cement. The cement has been replaced by rice husk ash, accordingly in the range with $0 \%, 10 \%, 20 \%$ and $30 \%$ by weight. Concrete mixture of M20 and M25 and M30, were produced, tested and compared in terms of compressive strengths with the Conventional concrete. These tests were carried out to evaluate the mechanical properties for the test results of $7,14,28,56$ and 90 days for Compressive strengths and Tensile \& Flexural Strengths at 28 days. The durability aspect of the samples for Acid attack, Alkaline attack and Sulphate attack was also tested. The result indicates that the FA, RHA and SCBA improve the Compressive Strength and durability of concrete.
\end{abstract}

Keywords: compressive strength,natural admixtures, M20, M25, M30, Durability, FA, RHA, SCBA etc,.

\section{Introduction}

The researchers are studying different agro-based waste materials in the present days. The major quantities of waste generated from agricultural sources include sugarcane bagasse, rice husk, and coconut husk. Reusing such waste as a sustainable construction material seems to be a suitable solution for the problem of landfilling and the high cost of building materials (Rabi et al 2009). In the current circumstance, the most serious issue of humanity on this planet is the earth contamination which causes environmental awkwardness. There are numerous reasons which deliver natural contamination. In the development business the primary material/fixing utilized for the creation of quality in cement will be cement. There will be parcel of discharge of carbon dioxide amid the generation of cement. The fundamental dependable industry for the emanation of carbon dioxide is the cement industry, on the grounds that the generation of one ton of Portland cement discharges give or take one ton of $\mathrm{CO} 2$ into the environment There are two unique sources of carbon dioxide discharge amid the creation of cement, the biggest source to function rotary kiln is the Combustion of fossil fuels andt he other one is the synthetic procedure where lime is calcinated through limestone in the cement kiln which additionally creates carbon dioxide. In 2014 around 3980 crores huge amounts of carbon dioxide are discharged on the planet and in that around $7 \%$ of carbon dioxide discharge is contributed from India.

Fly ash: Fly ash is a byproduct obtained from pulverized coal burnt in electric generation power plants. It is in the form of fine powder which has some sort of pozzolanic properties due to presence of luminous and siliceous materials that behaves like cement in the presence of water. After mixing with lime and water it forms a nearly similar compound to Portland cement. The fly ash produced by thermal power plants provide san resourceful byproduct material used in blended cement, mosaic tiles, and hollow blocks etc.

Fly ash is an economical material and used as a partial replacement for Portland cement in concrete. Usage of Flyash improves strength, segregation, and ease of pumping concrete. The rate of substitution typically specified is $1 \mathrm{~kg}$ to $1.65 \mathrm{~kg}$ of fly ash to $1 \mathrm{~kg}$ of cement. In spite of that, the amount of fine aggregate should be adjusted to accommodate fly ash additional volume.

Rice husk ash : Rice husk is an agricultural residue which accounts for $20 \%$ of the 649.7 million tons of rice produced annually worldwide. The burnt by-product residue of Rice Husk in the milling plants causes a threat to atmosphere and pollutes the fresh air. Therefore by using this rice husk ash as a supplementary material in concrete, we may help the society to breath fresh air.

Sugarcane bagasse ash : Sugarcane Bagasse, an abundantly produced agricultural waste, is the residue of sugarcane that isobtained after extraction of juice. The sugarcane Bagasse consists of approximately $45-50 \%$ of cellulose, $26 \%$ of hemicellulose and $23 \%$ of lignin along with traces of other compounds. Each ton of sugarcane generates approximately $26 \%$ of Bagasse (at a moisture content of 50\%) and $0.62 \%$ of residual ash when burned at $600-800^{\circ} \mathrm{C}$. 


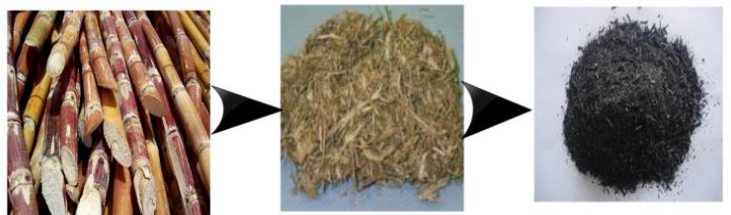

Objective Of The Study: Depending On The Suitability Of Bagasse Ash, It Can Be Used As Resource Material In The Following Applications:

Silica source as it contains high amount of silica in it.

Brick production as BA used as additive in making bricks that have high compressive strength and low water absorption bricks.

Farm fertilizer as it contains traces of potassium and phosphorus compounds etc.

To compare the tests results of fly ash, rice husk ash, and sugarcane Bagasse ash with the normal concrete.

To find the optimum usage of the percentage replacement of the fly ash, rice husk ash, baggage ash to the concrete.

\section{Literature Review}

Tony suman kanth $\mathrm{d} 1, \mathrm{k} \mathrm{u}$ muthu2 The real issue world facing today is the environment contamination. In construction field mainly by cement production which discharges pollutants bring about environment contamination. Usage of industrial waste we can decrease the contamination impact. In this aspect the geo polymer concrete comes to role i.e., in the present study to prepare the geo polymer concrete the normal Portland cement is completely supplemented with fly ash, sugarcane Bagasse ash and rice husk ash. Alkaline liquid are utilized for the binding of materials. The liquid utilized in this study for the polymerization are the solution of sodium silicate and sodium hydroxide. Distinctive percentage of sugarcane Bagasse ash and rice husk ash is utilized has the binders with fly ash. Fly ash is supplemented by including $0 \%, 10 \%, 30 \%$ and $50 \%$ of Bagasse ash and rice husk ash which is the bi product of sugarcane industry and rice mill respectively. The mechanical properties such as compressive split tensile and flexural strength of geopolymer is brought about in this report to know the role played by supplementing fly ash binders partially by sugarcane Bagasse ash and rice husk ash on the strength parameters of geopolymer concrete.

Geopolymer concrete with the replacement of Bagasse ash or rice husk ash up to $10 \%$ that is the optimum percentage can be utilized. One of any can be used depending on the availability possibility, if both are of same possibility or having equivalent accessibility chances than continuing for the replacement of Bagasse ash is better than the rice husk ash. With replacement of $30 \%$ to $50 \%$ of rice husk ash the strength gradually decreases for compression where as for the split tensile and the flexural strength properties there is a sudden decrease in strength which should be restricted being used.

\section{Collection of Materials}

Cement: Cement is a binder, a substance used in construction that sets and hardens and can bind other materials together. The most important types of cement are used as a component in the production of mortar in masonry, and of concrete- which is a combination of cement and an aggregate to form a strong building material. The ordinary Portland cement of 53 Grade is used in accordance with IS: 12269-1987. Properties of this cement were tested and listed here. Fineness of cement $=5 \%$,Specific gravity if cement $=3.15$, Standard Consistency of cement $=33 \%$ Initial setting time $=30$ minutes, Final setting time $=$ Not more than 10 hours.
Coarse aggregates: Crushed stone aggregate of $20 \mathrm{~mm}$ size is brought from nearby quarry. Aggregates of size more than $20 \mathrm{~mm}$ size are separated by sieving. Tests are carried in order to find out the Specific gravity $=2.9 \quad$ Fineness modulus $=7.5$.

Fine aggregates: Locally available fresh sand, free from organic matter is used. The result of sieve analysis confirms it to Zone-II (according to IS: 383-1970). The tests conducted and results plotted below. Specific gravity $=2.3$. Fineness modulus $=3.06$.

Fly ash : Fly ash is a fine powder which is a byproduct from burning pulverized coal in electric generation power plants. Fly ash is a pozzolana, a substance containing aluminous and siliceous material that forms cement in the presence of water. When mixed with lime and water it forms a compound similar to Portland cement.

Rice husk ash : Rice husk ash (RHA) is the ash which is obtained from burning the protected outer cover of Rice called husk. It consists of non-crystalline silicon dioxide ( $\mathrm{SiO} 2)$ with high specific surface area and high pozzolanic reactivity. The RHA can be found as natural materials, by-products or Industrial wastes. The chemical properties are similar to micro silica, Silica fume. Sugar cane bagasse ash : The sugarcane bagasse consists of approximately $50 \%$ of cellulose, $25 \%$ of hemicelluloses and $25 \%$ of lignin. Each ton of sugarcane generates approximately $26 \%$ of bagasse (at a moisture content of $50 \%$ ) and $0.62 \%$ of residual ash. The residue after combustion presents a chemical composition dominates by silicon dioxide ( $\mathrm{SiO} 2)$. In spite of being a material of hard degradation and that presents few nutrients, the ash is used on the farms as a fertilizer in the sugarcane harvests. In this experimental study sugarcane bagasse ash was collected from the J.M.S Sugar Cane Suppliers ,7-2-1862, Near Victory Function Hall, Erragadda, Sanath Nagar, Hyderabad, Telangana 500018.

Water: Generally potable water should be used. This is to ensure that the water is reasonable free from such impurities as suspended solids, organic matter and dissolved salts, which may adversely affect the properties of the concrete, especially the setting, hardening, strength, durability, pit value, etc.
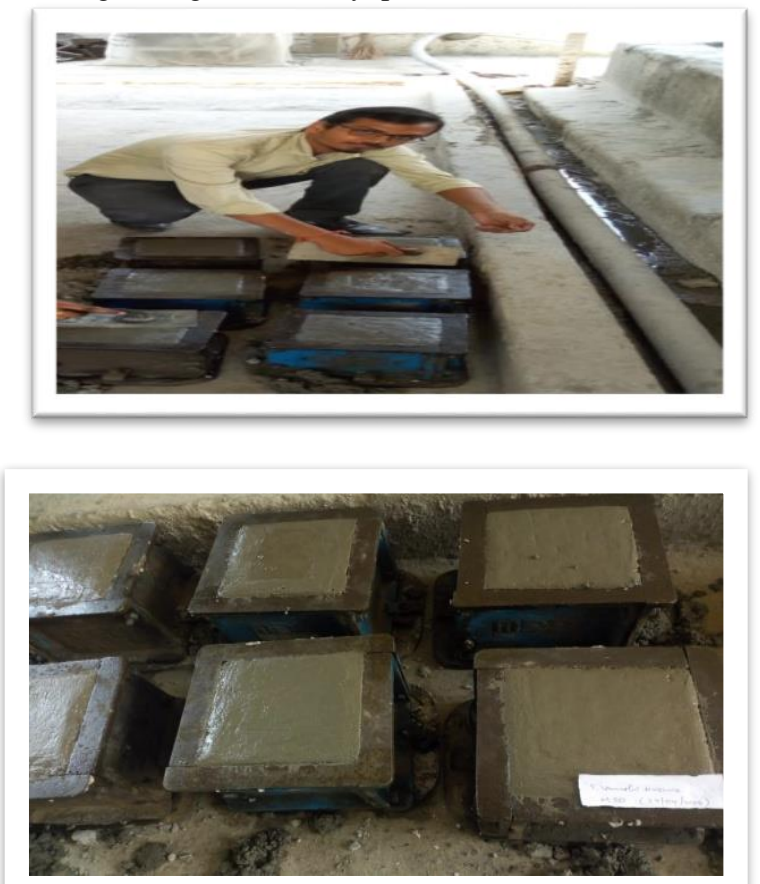

Mix Design and Quantity of Materials
1. Mix Proportion for Trail M20 is 1: 1.81:2.82 atw/c ratio of 0.50 


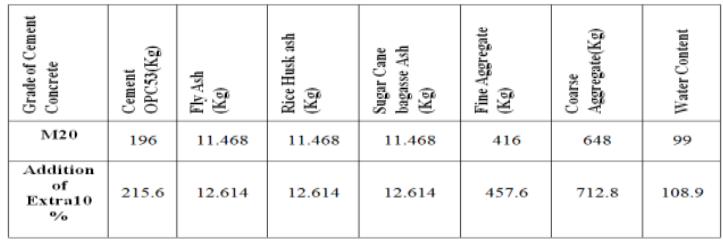

2. Mix Proportion for Trail M25 is 1: 1.19: 2.63. atw/c ratio of 0.43

\begin{tabular}{|c|c|c|c|c|c|c|c|}
\hline 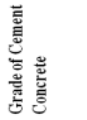 & 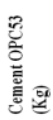 & 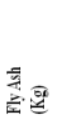 & 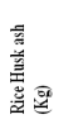 & 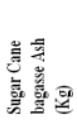 & 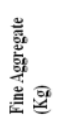 & 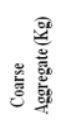 & 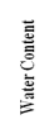 \\
\hline M25 & 230 & 13.462 & 13.462 & 13.462 & 320 & 708 & 116 \\
\hline $\begin{array}{c}\text { Addition } \\
\text { of } \\
\text { Extra10 } \\
\% \%\end{array}$ & 253 & 14.808 & 14.808 & 14.808 & 352 & 778 & 127.6 \\
\hline
\end{tabular}

3. Final trial mix for $M 30$ grade concrete is $1: 1.64: 2.55$ at w/c of 0.45

\begin{tabular}{|c|c|c|c|c|c|c|c|}
\hline 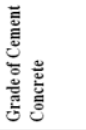 & 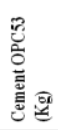 & 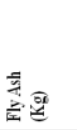 & 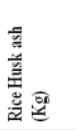 & 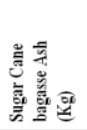 & 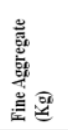 & 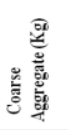 & 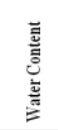 \\
\hline M30 & 215 & 12.431 & 12.431 & 12.431 & 413 & 642 & 114 \\
\hline $\begin{array}{c}\text { Addition } \\
\text { of } \\
\text { Extra10 } \\
\%\end{array}$ & 236 & 14.808 & 14.808 & 14.808 & 454.3 & 706.2 & 125.4 \\
\hline
\end{tabular}

4. Results and Discussions

1. M 20 GRADE OF CONCRETE RESULTS SLUMP CONE TEST \& COMPACTION FACTOR TEST

\begin{tabular}{|c|c|c|c|}
\hline \multicolumn{4}{|c|}{ M20 Results } \\
\hline S.no. & $\begin{array}{c}\text { \% Replacement } \\
\text { (R.H.A +FA+SBA) }\end{array}$ & $\begin{array}{l}\text { Slump value } \\
\text { In (mm) }\end{array}$ & Compaction factor \\
\hline 1 & $0 \%$ & 92 & 0.92 \\
\hline 2 & $10 \%$ & 90 & 0.90 \\
\hline 3 & $20 \%$ & 95 & 0.85 \\
\hline 4 & $30 \%$ & 100 & 0.76 \\
\hline \multicolumn{4}{|c|}{ M20 Concrete Slump value in $\mathrm{mm}$} \\
\hline \multirow{6}{*}{ 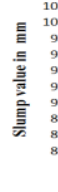 } & & & \\
\hline & & & \\
\hline & & & \\
\hline & & & \\
\hline & \multirow[t]{2}{*}{$0 \%$} & $20 \%$ & $30 \%$ \\
\hline & & Replacemen & \\
\hline
\end{tabular}

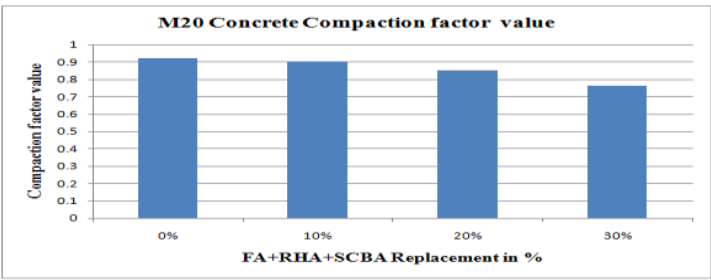

Compressive Strength Results

\begin{tabular}{|c|c|c|c|c|c|c|}
\hline \multirow{2}{*}{ S.no } & \multirow{2}{*}{$\begin{array}{c}\text { Type of Mix } \\
\text { (R.H.A+FA+SBA) }\end{array}$} & \multicolumn{3}{l}{$\begin{array}{l}\text { M20Compressive Strength in } \\
\text { (N/mm2) }\end{array}$} \\
\cline { 3 - 7 } & & 7 Days & 14 Days & 28 Days & 56 Days & 90 Days \\
\hline 1 & $0 \%$ & 12.85 & 15.52 & 22.56 & 23.45 & 26.42 \\
\hline 2 & $10 \%$ & 13.6 & 17.52 & 24.62 & 26.85 & 28.42 \\
\hline 3 & $20 \%$ & 15.62 & 20.52 & 26.7 & 28.4 & 29.5 \\
\hline 4 & $30 \%$ & 14.5 & 19.52 & 24.62 & 26.8 & 29.8 \\
\hline
\end{tabular}

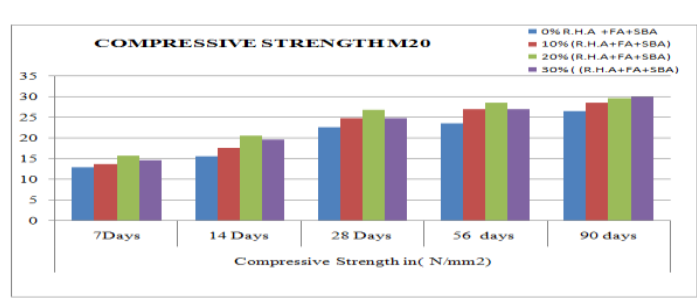

Split Tensile Strength Test Results

\begin{tabular}{|c|c|l|}
\hline \multirow{2}{*}{ S.no } & \multirow{2}{*}{$\begin{array}{c}\text { Type of Mix } \\
\text { (R.H.A+FA+SBA) }\end{array}$} & $\begin{array}{l}\text { M20 Split Tensile Strength in } \\
\text { (N/mm2) }\end{array}$ \\
\cline { 3 - 3 } & & 28 Days \\
\hline 1 & $0 \%$ & 5.42 \\
\hline 2 & $10 \%$ & 6.92 \\
\hline 3 & $20 \%$ & 7.42 \\
\hline 4 & $30 \%$ & 6.8 \\
\hline
\end{tabular}

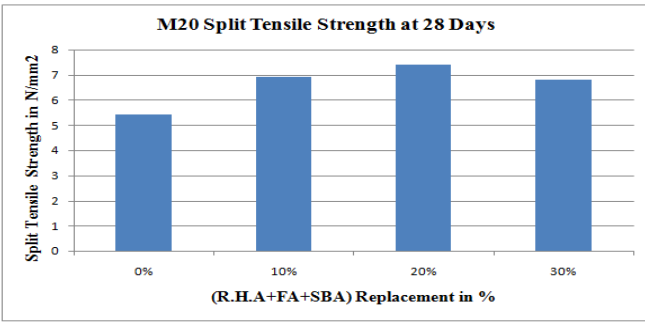

Flexural Strength Test Results:
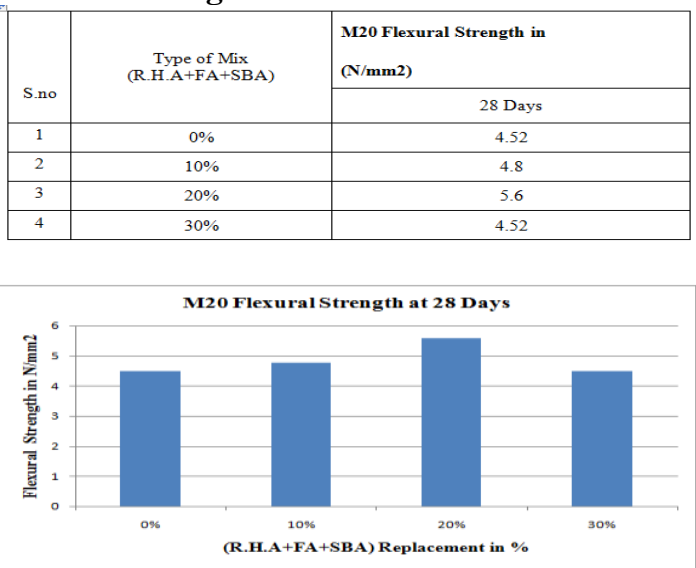

2. M 25 GRADE OF CONCRETE RESULTS Slump\& Compaction Factor of M25 Concrete

\begin{tabular}{|c|c|c|c|}
\hline \multicolumn{4}{|c|}{ M25 Results } \\
\hline S.no. & $\begin{array}{c}\text { \% Replacement } \\
\text { (R.H.A+FA+SBA) }\end{array}$ & $\begin{array}{c}\text { Slump value } \\
\text { In (mm) }\end{array}$ & Compaction factor \\
\hline 1 & $0 \%$ & 90 & 0.94 \\
\hline 2 & $10 \%$ & 88 & 0.92 \\
\hline 3 & $20 \%$ & 86 & 0.90 \\
\hline 4 & $30 \%$ & 85 & 0.89 \\
\hline
\end{tabular}




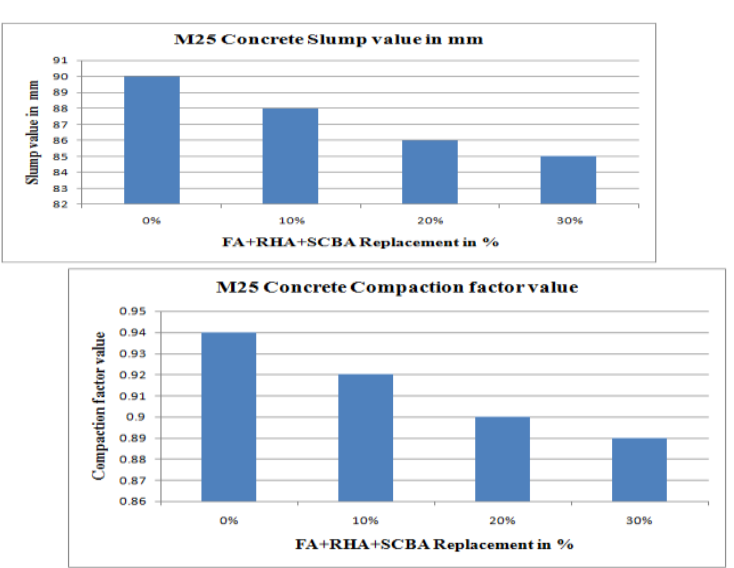

Compressive Strength Results

\begin{tabular}{|c|c|c|c|c|c|c|}
\hline \multirow{2}{*}{ S.no } & $\begin{array}{c}\text { Type of Mix } \\
\text { (R.H.A+FA+SBA) }\end{array}$ & \multicolumn{5}{l|}{$\begin{array}{l}\text { M25 Compressive Strength in } \\
\text { (N/mm2) }\end{array}$} \\
\cline { 3 - 7 } & & 7 Days & 14 Days & 28 Days & 56 Days & 90 Days \\
\hline 1 & $0 \%$ & 17.56 & 19.26 & 24.8 & 29.82 & 30.52 \\
\hline 2 & $10 \%$ & 18.5 & 20.56 & 29.8 & 32.8 & 35.6 \\
\hline 3 & $20 \%$ & 23 & 33.7 & 35.9 & 37.89 & 39.4 \\
\hline 4 & $30 \%$ & 19.8 & 29.32 & 27.84 & 30.85 & 31.5 \\
\hline
\end{tabular}

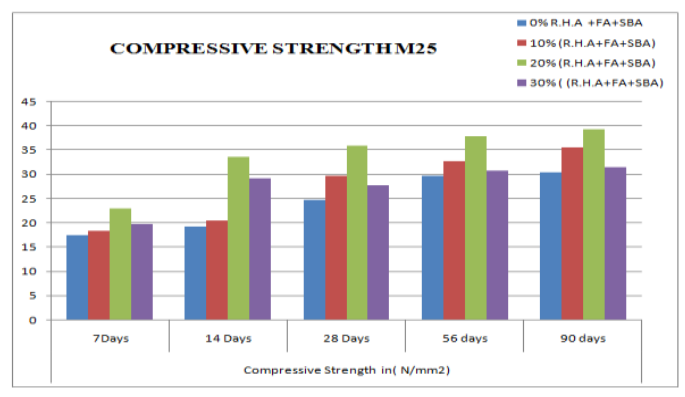

\section{Split Tensile Strength Test Results}

\begin{tabular}{|c|c|c|}
\hline \multirow{2}{*}{ S.no } & \multirow{2}{*}{$\begin{array}{c}\text { Type of Mix } \\
\text { (R.H.A+FA+SBA) }\end{array}$} & $\begin{array}{l}\text { M25 Split Tensile Strength in } \\
\text { (N/mm2) }\end{array}$ \\
\cline { 3 - 3 } & $0 \%$ & 28 Days \\
\hline 1 & $10 \%$ & 7.62 \\
\hline 2 & $20 \%$ & 8.4 \\
\hline 3 & $30 \%$ & 10.62 \\
\hline 4 & & 7.62 \\
\hline
\end{tabular}

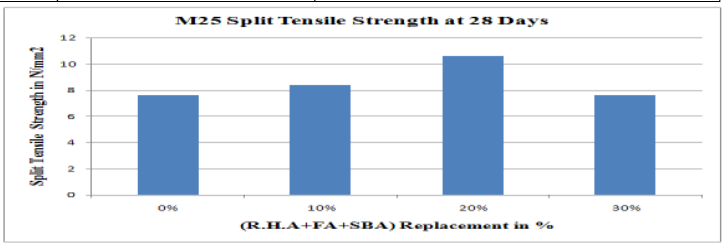

Flexural Strength Test Results:
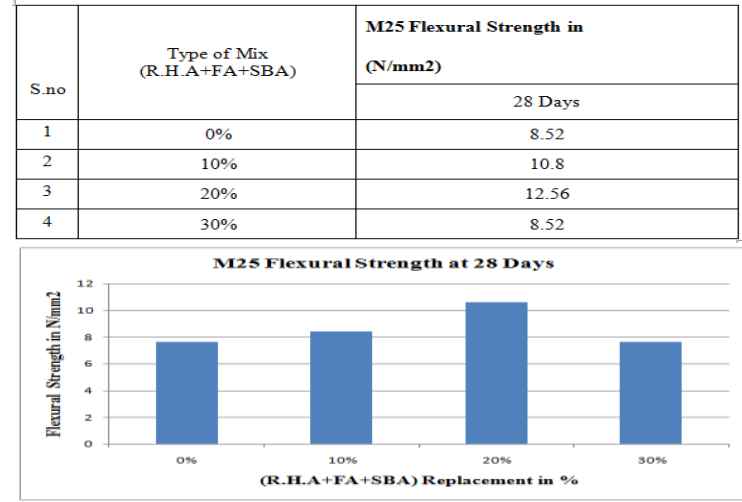

3. M30 GRADE OF CONCRETE TEST RESULTS Slump \& Compaction Factor of M30 Concrete:

\begin{tabular}{|c|c|c|c|}
\hline \multicolumn{4}{|c|}{ M30 Results } \\
\hline S.no. & $\begin{array}{c}\text { \%Replacement } \\
\text { (R.H.A +FA+SBA) }\end{array}$ & $\begin{array}{c}\text { Slump value } \\
\text { In (mm) }\end{array}$ & Compaction factor \\
\hline 1 & $0 \%$ & 89 & 0.92 \\
\hline 2 & $10 \%$ & 86 & 0.90 \\
\hline 3 & $20 \%$ & 84 & 0.89 \\
\hline 4 & $30 \%$ & 87 & 0.86 \\
\hline
\end{tabular}
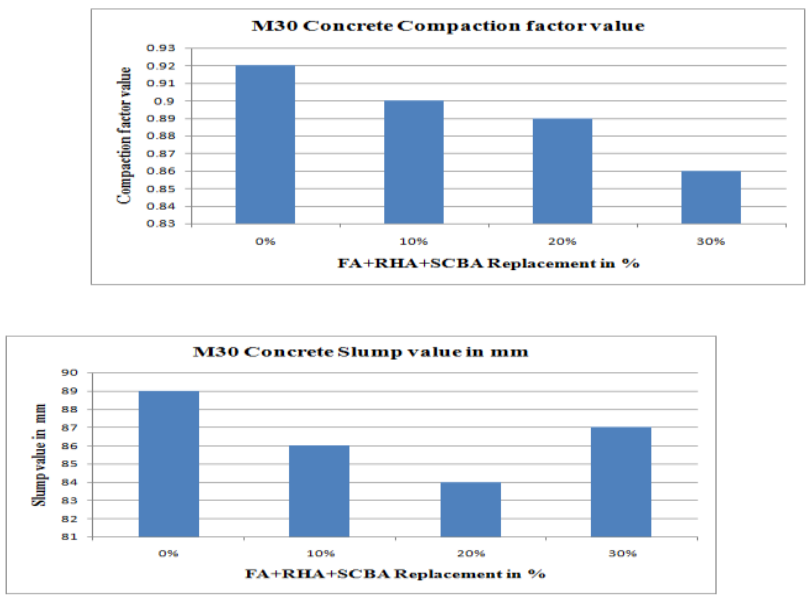

COMPRESSIVE STRENGTH RESULTS

\begin{tabular}{|c|c|c|c|c|c|c|}
\hline \multirow{2}{*}{ S.no } & $\begin{array}{c}\text { Type of Mix } \\
\text { (R.H.A+FA+SBA) }\end{array}$ & \multicolumn{5}{l|}{$\begin{array}{l}\text { M30 Compressive Strength in } \\
\text { (N/mm2) }\end{array}$} \\
\cline { 3 - 7 } & & 7 Days & 14 Days & 28 Days & 56 Days & 90 Days \\
\hline 1 & $0 \%$ & 18.98 & 28.91 & 35.6 & 36.42 & 39.3 \\
\hline 2 & $10 \%$ & 22.4 & 27 & 31 & 33.5 & 36.8 \\
\hline 3 & $20 \%$ & 23 & 33.7 & 35.9 & 37.25 & 39.2 \\
\hline 4 & $30 \%$ & 19.8 & 29.32 & 27.84 & 34.25 & 35.6 \\
\hline
\end{tabular}

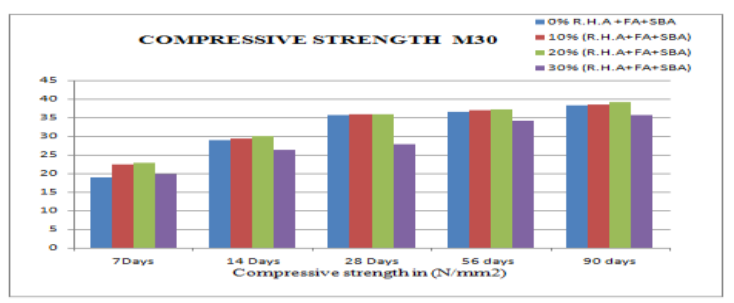

SPLIT TENSILE STRENGTH TEST RESULTS 


\begin{tabular}{|c|c|c|}
\hline \multirow{2}{*}{ S.no } & \multirow{2}{*}{$\begin{array}{c}\text { Type of Mix } \\
\text { (R.H.A+FA+SBA) }\end{array}$} & $\begin{array}{c}\text { M30 Split Tensile Strength in } \\
\text { (N/mm2) }\end{array}$ \\
\cline { 3 - 3 } & & 28 Days \\
\hline 1 & $0 \%$ & 12.82 \\
\hline 2 & $10 \%$ & 13.21 \\
\hline 3 & $20 \%$ & 13.53 \\
\hline 4 & $30 \%$ & 12.82 \\
\hline
\end{tabular}

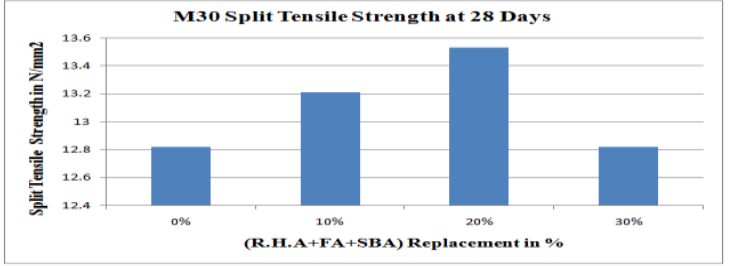

\section{FLEXURAL STRENGTH TEST RESULTS}

\begin{tabular}{|c|c|l|}
\hline \multirow{2}{*}{ S.no } & \multirow{2}{*}{$\begin{array}{c}\text { Type of Mix } \\
\text { (R.H.A+FA+SBA) }\end{array}$} & $\begin{array}{l}\text { M30 Flexural Strength in } \\
\text { (N/mm2) }\end{array}$ \\
\cline { 3 - 3 } & & 28 Days \\
\hline 1 & $0 \%$ & 10 \\
\hline 2 & $10 \%$ & 12.26 \\
\hline 3 & $20 \%$ & 13.5 \\
\hline 4 & $30 \%$ & 10 \\
\hline
\end{tabular}

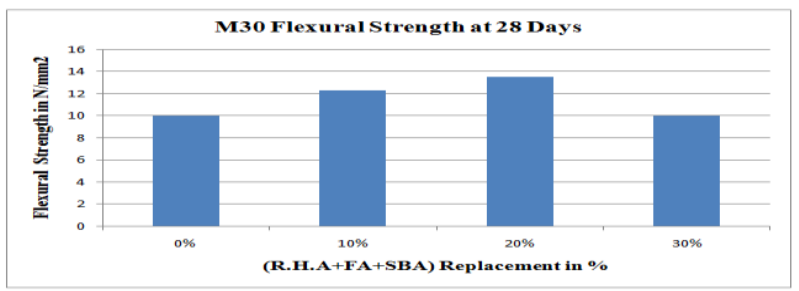

\section{Discussions}

\section{Comparisons in M20 design mix Vs Samples}

At 7,14,28,56 days the compressive strength values increase with increase in replacement of cement up to $20 \%$ and decrease at $30 \%$. At 90 days Compressive strength values increase with increase in replacement of cement from $0 \%$ to $30 \%$. It is observed that $20 \%$ replacement of cement is ideal at point of testing the M20 grade concrete specimens.

\section{Comparisons in M25 design mix Vs Samples}

At 7 days the compressive strength values increase with increase in replacement of cement up to $20 \%$ and decrease at $30 \%$. At $14,28,56,90$ days the compressive strength values significantly increase with increase in replacement of cement up to $20 \%$ and suddenly decreases with $30 \%$ replacement. It is observed that 20 $\%$ replacement of cement is ideal at any point of testing the M25 grade concrete specimens.

\section{Comparisons in M30 design mix Vs Samples}

At 7 days the compressive strength values increase with increase in replacement of cement up to $20 \%$ and decrease at $30 \%$. At $14,28,56,90$ days the compressive strength values decrease with increase in replacement of cement up to $10 \%$ and decreases with $30 \%$ replacement. It is observed that $20 \%$ replacement of cement is ideal at any point of testing the M30 grade concrete specimens.

\section{Conclusions}

Below is the list of Observations \& Conclusions of the current experimental project undertaken, based on the Materials chosen, Methodology adopted, Procedures followed and Test results obtained:

1. Based on the present experimental results, the physical and chemical composition of the Bagasse Ash and Rice Husk Ash is essentially responsible for the later hydration process. Their fineness and specific surface area coverage are highly suitable for the workability of concrete which was more than expected

2. The Slump value is decreasing with grade of concrete due to mineral admixtures which absorb the water content.

3. The compaction Factor is decreasing with increasing in the replacement of cement quantity.

4. Positive results were obtained by subjecting these recommended concrete mixes to additional compressive strength tests, flexural strength tests, tensile strength tests, and durability tests.

5. There is a significant increase in the compressive strength, Split Tensile strength and Flexural Strengths due to the addition of mineral admixturesup to $20 \%$ and thereafter it is decreasing.

6. Bagasse Ash and Rice Husk Ash, contributes to useful disposal of these waste materials, and reduces consumption of cement, thus lowering adverse effects on the environment.

7. The Concrete thus obtained by partial replacement of cement with natural admixtures are durable in long term use.

8. At $20 \%$ to $30 \%$ replacement there observed a change in the decreased rate of strengths and in Flexural Strengths and compressive strengths than the rate of change at 10 $\%$ to $20 \%$.

9. The Compressive Strength and Durability values are increasing with the age of concrete specimen which is observed in graphs from 56 days to 90 days values.

\section{Future Scope of Study}

- Increasing the quantity of the replacement of cement with more proportion of Sugarcane Bagasse ash and testing for the better reducing of cement quantity.

- The design mixes with increasing in the quantity of Sugarcane Bagasse ash alone up to $20 \%, 30 \%$ keeping it constant and changing the Rice husk proportionately varying in higher grades M35 and M40 Design mixes.

- With this project, the optimum proportion of mineral admixtures is favorable for strength and Durability at $20 \%(\mathrm{FA}+\mathrm{RHA}+\mathrm{SBA})$. Thereforethere can be a future scope to find out the exact proportion in between $20 \%$ and $30 \%$ at which the strength and durability values are decreasingin various grades of design mixes.

- As fly ash has become the most well popular admixture, Rice Husk Ash and Bagasse Ash are also need to be popularized with its effective usage in the concrete industries.

- For smaller constructions if these blended concretes are set to be adapted, then huge quantity of cement utilization can be reduced and thereby cost of the construction is reduced along with ecology balance.

\section{References}


[1] Concrete Technology text book, M.S. Shetty

[2] IS 456-2000 : Plain and Reinforced Concrete- Code of Practice

[3] IS 10262-2009 : Concrete Mix Proportioning-Guidelines

[4] IS 12269- 2013: Ordinary Portland Cement.53 Grade Specification

[5] IS 9103 (1999) : specification for concrete admixtures

[6] IS 516 - 1959 :Method of test for strength of concrete.

[7] IS12269 -19198 Specification for 53 Grade Ordinary Portland cement.

[8] Triple blending of cement concrete with natural admixtures. 